\title{
Electroconvulsive therapy electrode placement for bipolar state-related targeted engagement
}

\author{
Christopher C. Abbott ${ }^{*}$ (D) Jeremy Miller, Megan Lloyd and Mauricio Tohen
}

\begin{abstract}
Background: Electroconvulsive therapy (ECT) is an effective treatment for all bipolar states. However, ECT remains underutilized, likely stemming from stigma and the risk of neurocognitive impairment. Neuroimaging research has identified state-specific areas of aberrant brain activity that may serve as targets for therapeutic brain stimulation. Electrode placement determines the geometry of the electric field and can be either non-focal (bitemporal) or more focal (right unilateral or bifrontal). Previous research has shown that electrode placement can impact clinical and cognitive outcomes independent of seizure activity. This review critically examines the evidence that focal (unilateral or bifrontal) electrode placements target specific aberrant circuitry in specific bipolar states to optimize clinical outcomes. We hypothesize that optimal target engagement for a bipolar state will be associated with equivalent efficacy relative to bitemporal non-focal stimulation with less neurocognitive impairment.

Methods: We performed a literature search in the PubMed database. Inclusion criteria included prospective, longitudinal investigations during the ECT series with specific electrode placements within a bipolar state from 2000 to 2018.

Results: We identified investigations that met our inclusion criteria with bipolar mania $(n=6)$, depression $(n=6)$, mixed $(n=3)$ and catatonia $(n=1)$ states. These studies included clinical outcomes and several included cognitive outcomes, which were discussed separately.

Conclusions: While the heterogeneity of the studies makes comparisons difficult, important patterns included the reduced cognitive side effects, faster rate of response, and equivalent efficacy rates of the focal electrode placements (right unilateral and bifrontal) when compared to non-focal (bitemporal) placement. Further avenues for research include more robust cognitive assessments to separate procedure-related and state-related impairment. In addition, future studies could investigate novel electrode configurations with more specific target engagement for different bipolar states.
\end{abstract}

Keywords: Bipolar disorder, Electroconvulsive therapy, Electrode placement

\section{Introduction}

Treatment resistance to pharmacotherapy in bipolar disorder is unfortunately common across all phases of the illness (Thirthalli et al. 2012). Treatment resistance to pharmacotherapy is dependent on the phase of illness and has multiple definitions and thresholds. In the context of bipolar depression, treatment resistance is

\footnotetext{
*Correspondence: cabbott@salud.unm.edu

Department of Psychiatry \& Behavioral Sciences, University of New

Mexico Health Sciences Center, University of New Mexico School

of Medicine, Albuquerque, NM 87131, USA
}

commonly defined as a failure of two antidepressant trials with concurrent treatment with a mood stabilizer (Gitlin 2006). Despite optimal treatment in the Systematic Treatment Enhancement Program for Bipolar Disorder (STEP-BD), $25 \%$ of the bipolar subjects failed to achieve symptom remission in 2 years of follow-up (Perlis et al. 2006). Treatment resistance and acuity are common indications for electroconvulsive therapy (ECT) in bipolar patients. ECT is effective in mania, mixed, and depressed states of bipolar disorder as well as maintenance phases of treatment (Medda et al. 2014). Despite 
the overwhelming effectiveness as a true mood stabilizer, patients and clinicians do not consider ECT earlier in the treatment algorithm because of the risk of neurocognitive impairment (Thirthalli et al. 2012; MacQueen et al. 2007; UK ECT Review Group 2003). The risk of ECTmediated neurocognitive impairment is related to both patient (age, medical comorbidities, cognitive reserve) and treatment related factors (electrode placement, stimulation parameters, treatment number and frequency) (McClintock et al. 2014). The risk and benefit ratio may be optimized by individualizing ECT treatment to maximize mood stabilizing properties while minimizing neurocognitive impairment.

While the exact mechanism of action remains elusive, the therapeutic components of ECT include electric stimulation and generalized seizure activity. Electrode placement dictates the geometry of the electric field and, in conjunction with pulse amplitude, determines the percentage of activated brain volume (Peterchev et al. 2010). The anatomic location and amount of electric field strength may be related to clinical outcomes (Abbott et al. 2016). Bitemporal (BT) electrode placement is the oldest and most effective electrode placement for depressive episodes with respect to clinical efficacy and speed of response (Kellner et al. 2010). BT electrode placement is also the most non-focal method of stimulation and is associated with the greatest risk of neurocognitive impairment (Semkovska et al. 2011). Stimulation of the medial temporal lobes, independent of generalized seizure activity, is associated with increased risk of neurocognitive impairment and prompted efforts to develop more focal methods of stimulation that spare the hippocampus (Nobler et al. 2001; Sackeim et al. 1996; Nahas et al. 2013). For example, bifrontal and right unilateral electrode placement have more targeted engagement to the frontal and non-dominant hemisphere, respectively, relative to the non-focal bitemporal electrode placements.

The more focal electrode placements have unique patterns of brain stimulation that may have differential effectiveness in specific bipolar states. The older lateralization hypothesis of mood control suggests that left hemisphere stimulation may be effective in treating mania (Sackeim et al. 1982). More recent neuroimaging investigations have not confirmed state-related differences in laterality but have identified several candidate circuits for targeted engagement within the corticolimbic model of bipolar disorder (Blumberg et al. 2003; Strakowski et al. 2011; Brooks and Vizueta 2014; Strakowski et al. 2016). Critically, the large-scale networks such as sensorimotor and default mode networks may have unique patterns for depressive and manic phases of bipolar disorder (Martino et al. 2016). Extending state-related neuroimaging biomarkers to different bipolar states suggests that matching the stimulation pattern of the more focal electrode placements (unilateral or bifrontal) with the bipolar state should improve clinical outcomes (match the effectiveness of bitemporal electrode placement with reduced cognitive impairment). Limited evidence suggests that bifrontal electrode placement and prefrontal targeted engagement may have improved efficacy for mania (Blumenfeld et al. 2003). In contrast, right unilateral electrode placement may be ineffective for mania (Small 1985; Small et al. 1985; Milstein et al. 1987) but effective for depressive states with medial temporal lobe engagement (Abbott et al. 2014a). Thus, state-related electrode placements for optimal targeted engagement has the potential to optimize the risk/benefit ratio for ECT in bipolar disorder. However, neuroimaging has yet to confirm targeted engagement with specific electrode placements and bipolar states despite ample evidence with unipolar depression subjects (and combined unipolar and bipolar subjects) (Abbott et al. 2014b). Furthermore, the relative ineffectiveness of right unilateral electrode placement (and medial temporal lobe engagement) for mania is controversial and is based on older studies that did not utilize supra-threshold charge required for improved efficacy with unilateral electrode placements.

\section{Objectives of this review}

Efforts to develop more focal stimulation are contingent on identification of state-related anatomic regions for target engagement. Here, we explore the existing evidence of differences in clinical outcomes among three different electrode placements (bitemporal, right unilateral, or bifrontal) for different bipolar states (mania, depressed, mixed, or catatonic episodes). We focused on prospective investigations and highlight the few studies that compared different electrode placements within a specific bipolar state. We hypothesized that the more focal electrode placement (e.g. bifrontal, right unilateral) would target the state-specific neuroanatomic structures implicated in the pathology of a bipolar state (prefrontal cortices for mania, medial temporal lobes for depression), thus maintaining efficacy of bitemporal electrode placement while decreasing the risk of neurocognitive impairment.

\section{Methods}

We conducted a PubMed search with the following MeSH terms: "Bipolar Disorder/therapy"[MAJR]) AND "Electroconvulsive Therapy/methods"[MAJR] between January 1, 2000 and December 31, 2018. We selected this date range to acknowledge the development of clinically effective right unilateral supra-threshold (6x's 
seizure threshold treatments) (Sackeim et al. 2000). Unilateral ECT investigations prior to this date used sub-optimal dosing (seizure threshold or low dose) with right unilateral ECT. Inclusion criterion included prospective investigations that included information on bipolar state (manic, mixed, depressed, subsyndromal, and catatonic) and electrode placement (bitemporal, right unilateral and bifrontal). Exclusion criteria included the following: (1) investigations that did not separate bipolar and unipolar depression subjects, (2) investigations focused exclusively on the maintenance phase of treatment, (3) investigations that did not include a final assessment at the end of the ECT series, and (4) review articles, case reports or case series. The exclusion of maintenance ECT from this search strategy was based on the role of state-specific targeted engagement that may not be applicable to maintenance phases of treatment. Identification: Our initial PubMed search identified 106 investigations. Screening: We reviewed abstracts and titles to select 24 for detailed review. We excluded two ECT bipolar mania investigation: a retrospective chart review (Thirthalli et al. 2009) and a case series with no summary statistics (Anand 2016). A previous meta-analysis (Dierckx et al. 2012) concluded that ECT was equally effective in bipolar and unipolar depression; however, it did not include electrode placements (Dierckx et al. 2012). We excluded one investigation that did not include information on electrode placement in bipolar and unipolar depression (Prudic et al. 2004). Two investigations were excluded as retrospective chart reviews (Grunhaus et al. 2002; Hallam et al. 2009). Three investigations did not separate bipolar and unipolar depressed subjects (Heikman et al. 2002; Bailine et al. 2000; Ranjkesh et al. 2005). Eligibility and Identification: We finalized our review with the selection of 14 ECT bipolar investigations for qualitative synthesis [one investigation reported clinical and cognitive results separately (Kessler et al. 2014; Schoeyen et al. 2015) and another large investigation reported results from all bipolar states (Perugi et al. 2017)]. We organized the results of our review based on bipolar state and highlight the investigations that directly compared electrode placements.

\section{Results: ECT electrode placement and bipolar phase}

We have summarized the included investigations and representative electric fields for bitemporal, bifrontal and right unilateral electrode placements (single subject, 800 milliampere pulse amplitude) in Fig. 1.We have also summarized our findings in Tables 1, 2, 3 and 4.

\section{Bipolar Mania}

\section{Electrode placement comparisons}

Two investigations compared bitemporal with bifrontal electrode placement (Hiremani et al. 2008; Barekatain et al. 2008). Although both investigations included small samples $(<20)$, the results demonstrated similar effectiveness with both bifrontal and bitemporal electrode placements. Barekatain et al. (2008) compared bifrontal at 1.5 times seizure threshold and bitemporal at seizure threshold. Post-ECT YMRS scores were equivalent for both arms, but attrition was notable in this small study with only 8 of 14 (57\%) subjects in the bitemporal arm and 10 of 14 subjects (71\%) in the bifrontal arm completing the study. Hiremani et al. (2008) compared bifrontal at 1.5 times seizure threshold and bitemporal at 1.5 times seizure threshold. BF had a faster rate of response evident by the third ECT treatment, but the overall response rates were equivalent ( $88 \%$ response for bifrontal, $72 \%$ for bitemporal).

\section{No electrode placement comparisons}

Four investigations used one electrode placement (either bitemporal or bifrontal) and focused on stimulus intensities, concurrent psychotropic medications, and anesthetic augmentation strategies. One investigation used bitemporal electrode placement and compared two different stimulation intensities in subjects with bipolar mania with brief pulse ECT (1.5 ms) (Mohan et al. 2009). This investigation had the largest sample size for ECTmania with 26 subjects in the "seizure threshold" and 24 subjects in the "2.5 times seizure threshold" groups. The primary outcome was the Young Mania Rating Scale (YMRS). The results demonstrated very high and equivalent remission rates $(88 \%)$ in each arm. The second investigation to use bitemporal electrode placement compared two groups randomized to remifentanil or normal saline to improve clinical outcomes (Rezaei et al. 2012). Overall response rates were not recorded, but both arms demonstrated an equivalent reduction in YMRS. The third bitemporal ECT investigation assessed response rates from a community sample and demonstrated a $75 \%$ response rate (Perugi et al. 2017). The only study to focus exclusively on bifrontal electrode placement in mania compared two groups randomized to continue or discontinue sodium valproate (Jahangard et al. 2012). The two groups had an equivalent reduction in YMRS at the "primary" mid-series assessment (after the sixth ECT treatment) but notable attrition (69\%) by the end of the ECT series. 


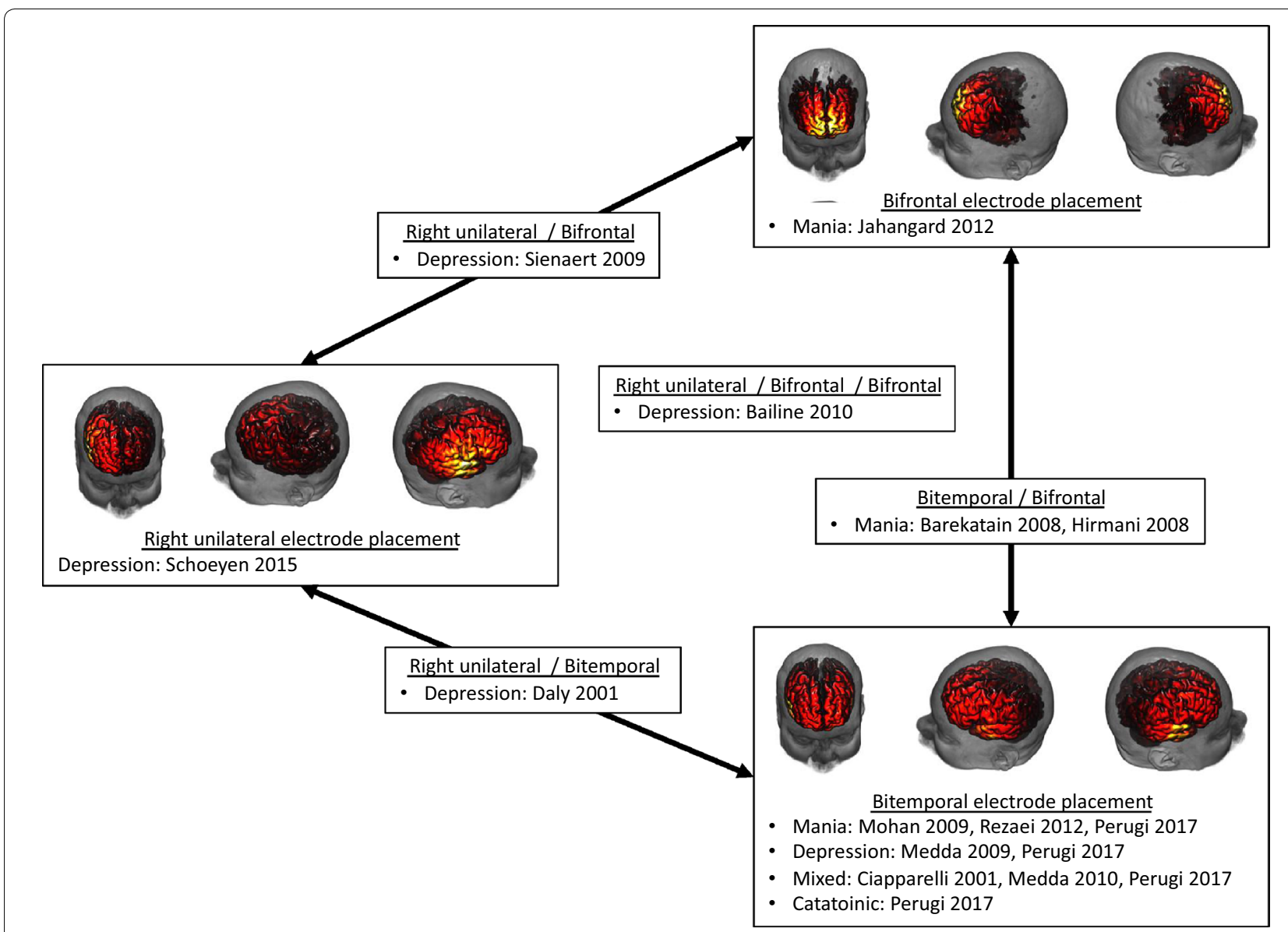

Fig. 1 Electric field modeling for bitemporal, right unilateral and bifrontal electrode placements with the associated studies included in this review. The electric field is modeled for 800 milliamperes with a threshold of $0.35 \mathrm{~V} / \mathrm{cm}$ (threshold for neuronal firing)

\section{Summary}

We are unable to make definitive comparisons between the investigations focused on a single electrode placement due to attrition and inconsistent reporting of clinical ratings. However, both bifrontal and bitemporal electrode placements appear to be effective for mania independent of alternative study aims (comparison of stimulation intensities or pharmacological augmentation strategies). Notably, bifrontal may be associated with a faster rate of response relative to bitemporal electrode placement, but larger studies are needed to prove this relationship.

\section{Bipolar Depression}

\section{Electrode placement comparisons}

Three investigations compared differences in clinical outcomes among bipolar patients with different electrode placements (Daly et al. 2001; Sienaert et al. 2009; Bailine et al. 2010). Daly et al. (2001) focused on the dose-finding studies with right unilateral and bitemporal electrode placements with different stimulation intensities (right unilateral from seizure threshold to six times threshold, bitemporal from seizure threshold to 2.5 times threshold). For purposes of this review, we focused on the results for the supra-threshold stimulations: right unilateral at six times threshold and bitemporal at 2.5 times threshold. The sub-sample in this analysis was very small ( $n=6$ for right unilateral, $n=14$ for bitemporal). The right unilateral supra-threshold treatments included a very small sample $(n=6)$ but $100 \%$ response and a faster rate of response for the bipolar depressed ( $7 \pm 2$ treatments) relative to the unipolar depressed subjects $(9 \pm 2)$. The bitemporal supra-threshold treatments also had a robust response (86\%). Sienaert et al. (2009) assessed right unilateral and bifrontal electrode placement in a sample of unipolar and bipolar patients. Results did not reveal any diagnostic or electrode placement differences, but bipolar subjects had a faster rate of response. Bailine et al. (2010) assessed the efficacy of right unilateral, 


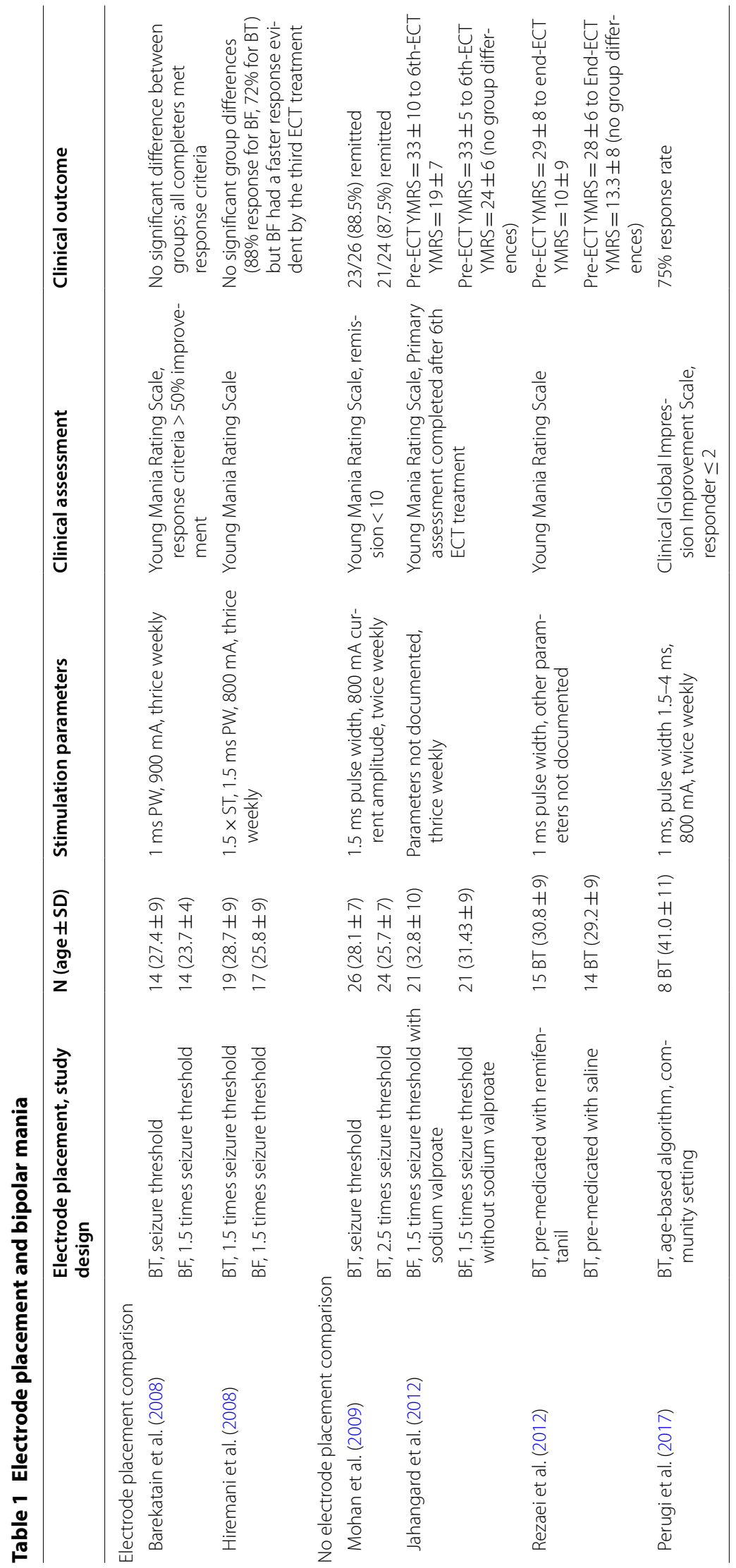




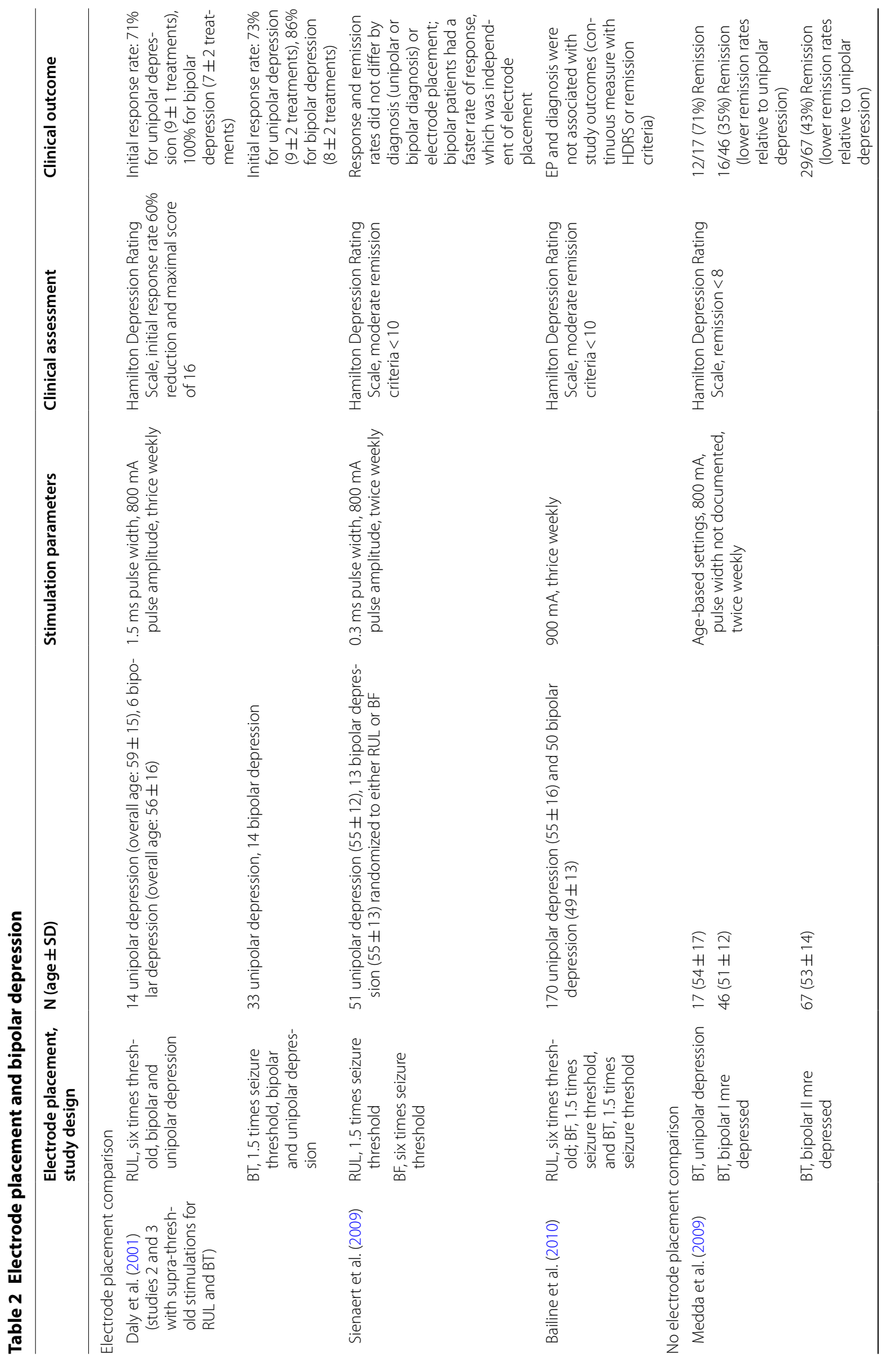




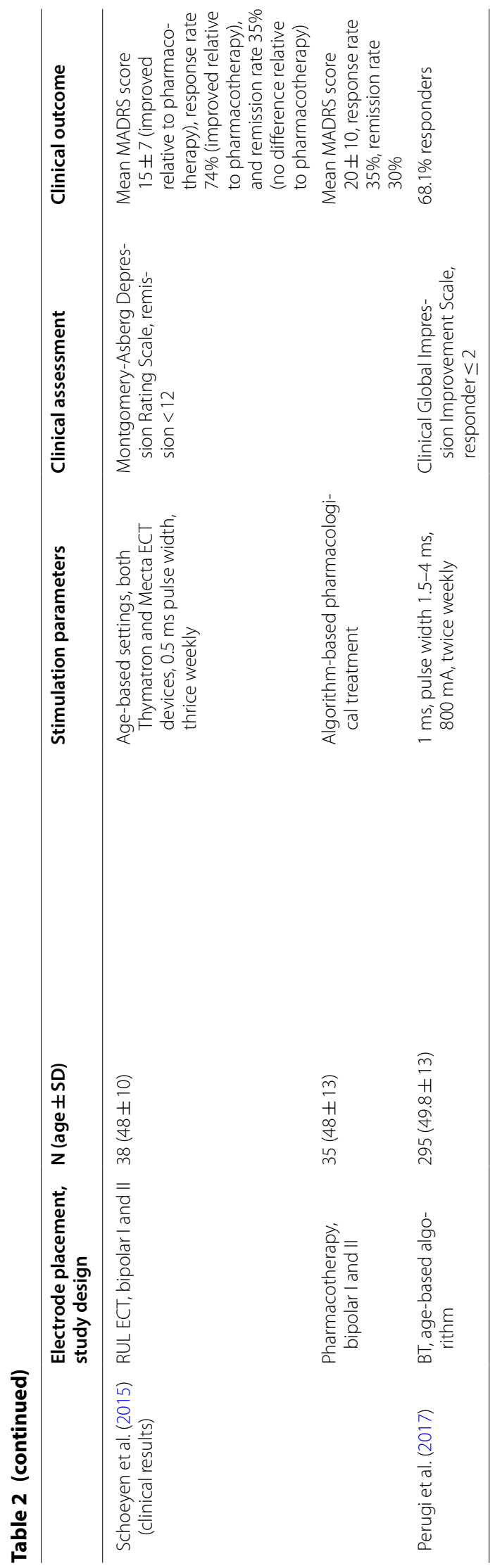


bifrontal, and bitemporal electrode placements in a large sample of unipolar $(\mathrm{n}=170)$ and bipolar subjects $(\mathrm{n}=50)$. Electrode placement and diagnosis (bipolar or unipolar depression) were not significant. Results from each electrode placement were not reported separately.

\section{No electrode placement comparisons}

Three investigations used one electrode placement (bitemporal or right unilateral) to establish outcomes in a large community sample (Perugi et al. 2017), compare differential outcomes across diagnostic categories (Medda et al. 2009), or differences in clinical outcomes relative to pharmacotherapy (Schoeyen et al. 2015). Medda et al. (2009) used bitemporal electrode placement to compare clinical outcomes across three different diagnostic categories: unipolar depression, bipolar I, and bipolar II subjects. The unipolar depressed group was the smallest group but had better rates of remission (12 subjects went to remission out of $17,71 \%$ remission rate) relative to bipolar I $(16 / 46,35 \%)$ and bipolar II $(29 / 67$, $43 \%$ ). Schoeyen et al. (2015) used a randomized controlled trial comparing right unilateral electrode placement (age-based formula) relative to pharmacotherapy for bipolar depression. The right unilateral arm had more clinical improvement and higher response rates relative to the pharmacotherapy arm, but the remission rates (35\% in the ECT arm) were similar. Perugi et al. (2017) conducted the largest study to date on bipolar and ECT (total $\mathrm{n}=522$, bipolar depression $\mathrm{n}=295$ ). The study used bitemporal electrode placement and found a high response rates in bipolar depression (68\%, response defined as Clinical Global Impression Improvement Subscale $(\mathrm{CGI}) \leq 2$ or "much improved").

\section{Summary}

Perugi et al. (2017) established the rate of response with bipolar depression and bitemporal electrode placement at $68 \%$ with a large sample of $\sim 300$ subjects. The different outcome measures associated with each study (CGI in the Perugi investigation compared to traditional depression ratings with rigorous remission criteria) complicates study and electrode placement comparisons. The low remission rates in the Schoeyen investigation prompted debate regarding right unilateral electrode placement in ECT, but the remission rates are comparable to an earlier bitemporal investigation (Schoeyen et al. 2015; Medda et al. 2009; Kellner and Fink 2015; Kotzalidis et al. 2015). The investigations comparing different types of electrode placements (right unilateral, bifrontal and bitemporal) included both unipolar and bipolar subjects that may have been underpowered to detect differences in response or remission rates within the bipolar group (Daly et al. 2001; Sienaert et al. 2009; Bailine et al. 2010).

\section{Bipolar Mixed and Catatonia}

We identified three investigations focused on ECT and bipolar mixed episodes (Perugi et al. 2017; Ciapparelli et al. 2001; Medda et al. 2010). We also identified one investigation that assessed ECT response with bipolar catatonia (Perugi et al. 2017). All investigations (for both bipolar mixed and catatonia) used bitemporal electrode placement and had similar efficacy irrespective of outcome measure. The initial efficacy favoring bipolar mixed relative to bipolar depression (Ciapparelli et al. 2001) was not replicated in a later study, which demonstrated similar, robust response rates for both depressed and mixed episodes (Medda et al. 2010). The bitemporal investigation with catatonia verified the expected high rate of response with this indication (Perugi et al. 2017).

\section{Bipolar state, Electrode Placement and Cogntion}

\section{Mania}

Two investigations assessed ECT-mediated neurocognitive impairment with bitemporal electrode placement in subjects with mania (Mohan et al. 2009; Rezaei et al. 2012). Both investigations demonstrated decline in cognitive performance with the Mini Mental State Exam (Mohan et al. 2009; Rezaei et al. 2012) and the Weschler Memory Scale (Rezaei et al. 2012). Two investigations measured longitudinal cognitive performance in subjects receiving bifrontal and bitemporal electrode placements (Hiremani et al. 2008; Barekatain et al. 2008). Hiremani et al. (2008) included a thorough cognitive assessment but did not find group differences with bifrontal or bitemporal electrode placements. In contrast, Barekatain et al. (2008) found group differences after the sixth ECT treatment with improved cognitive scores in the bifrontal arm.

\section{Depression}

Only one investigation assessed longitudinal cognitive performance during ECT with bipolar depression. Kessler et al. (2014) assessed cognitive performance with the MATRICS Consensus Cognitive Battery, and Autobiographical Memory Interview-Short Form in the right unilateral ECT and pharmacotherapy arms. Both groups demonstrated improvement in every domain of the MATRICS Consensus Cognitive Battery. However, the right unilateral ECT arm had reduced consistency with the Autobiographical Memory Interview-Short Form.

\section{Summary}

Although the evidence is sparse, the more focal ECT electrode placements may be associated with less ECT mediated neurocognitive impairment irrespective of 
Table 3 Electrode placement and bipolar mixed and bipolar catatonia

\begin{tabular}{|c|c|c|c|c|c|}
\hline & $\begin{array}{l}\text { Electrode placement, } \\
\text { study design }\end{array}$ & $\mathrm{N}($ age $\pm \mathrm{SD})$ & Stimulation parameters & Clinical assessment & Clinical outcome \\
\hline \multicolumn{6}{|l|}{ Mixed episodes } \\
\hline \multirow[t]{2}{*}{$\begin{array}{l}\text { Ciapparelli et al. } \\
\text { (2001) }\end{array}$} & BT, bipolar mixed & $41(38 \pm 12)$ & $\begin{array}{l}1 \text { to } 2 \text { ms pulse width, } \\
550 \text { to } 800 \text { mA cur- } \\
\text { rent amplitude, twice } \\
\text { weekly }\end{array}$ & \multirow{2}{*}{$\begin{array}{l}\text { Montgomery-Asberg } \\
\text { Depression Rating } \\
\text { Scale (response defined } \\
\text { as }>50 \% \text { reduction), } \\
\text { Brief Psychiatric Rating } \\
\text { Scale, and Clinical } \\
\text { Global Impression } \\
\text { (response defined } \\
\text { as } \leq \text { "mildly ill") }\end{array}$} & $\begin{array}{l}\text { CGI response crite- } \\
\text { ria }=56 \%, \text { MADRS } \\
\text { response crite- } \\
\text { ria }=78 \% \text {, higher } \\
\text { response rates for } \\
\text { mixed episode subjects }\end{array}$ \\
\hline & BT, bipolar depressed & $23(41 \pm 14)$ & & & $\begin{array}{l}\text { CGI response crite- } \\
\text { ria }=26 \%, \text { MADRS } \\
\text { response criteria = 52\% }\end{array}$ \\
\hline \multirow[t]{2}{*}{ Medda et al. (2010) } & BT, bipolar mixed & $50(39 \pm 13)$ & $\begin{array}{l}\text { Age-based formula, } \\
1.0 \text { ms pulse width, } \\
800 \text { mA current ampli- } \\
\text { tude, twice weekly }\end{array}$ & \multirow{2}{*}{$\begin{array}{l}\text { Hamilton Depression } \\
\text { Rating Scale (response } \\
\text { defined as > 50\% reduc- } \\
\text { tion, remission } \leq 8 \text { ), } \\
\text { Brief Psychiatric Rating } \\
\text { Scale, Young Mania } \\
\text { Rating Scale, and } \\
\text { Clinical Global Improve- } \\
\text { ment Scale (response } \\
\text { defined as } \leq \text { "much } \\
\text { improved", remission } \\
\text { rate as } \leq \text { "very much } \\
\text { improved") }\end{array}$} & $\begin{array}{l}\text { CGI response crite- } \\
\text { ria }=76 \% \text {, similar } \\
\text { response and remis- } \\
\text { sion rates among both } \\
\text { groups irrespective of } \\
\text { rating scale }\end{array}$ \\
\hline & BT, bipolar depressed & $46(51 \pm 12)$ & & & $\begin{array}{l}\text { CGI response crite- } \\
\text { ria }=67 \%\end{array}$ \\
\hline Perugi et al. (2017) & BT, age-based algorithm & $197(44 \pm 13)$ & $\begin{array}{l}1 \mathrm{~ms} \text {, pulse width } \\
1.5-4 \mathrm{~ms}, 800 \mathrm{~mA} \text {, twice } \\
\text { weekly }\end{array}$ & $\begin{array}{l}\text { Clinical Global Impression } \\
\text { Improvement Scale, } \\
\text { responder } \leq 2\end{array}$ & $72.9 \%$ responders \\
\hline \multicolumn{6}{|l|}{ Catatonic episodes } \\
\hline Perugi et al. (2017) & BT, age-based algorithm & $26(49.50 \pm 13)$ & $\begin{array}{l}1 \mathrm{~ms} \text {, pulse width } \\
1.5-4 \mathrm{~ms}, 800 \mathrm{~mA} \text {, twice } \\
\text { weekly }\end{array}$ & $\begin{array}{l}\text { Clinical Global Impression } \\
\text { Improvement Scale, } \\
\text { responder } \leq 2\end{array}$ & $80.8 \%$ responders \\
\hline
\end{tabular}

Table 4 Electrode placement and cognition

\begin{tabular}{|c|c|c|c|}
\hline & Electrode placement & Cognitive assessment & Cognitive outcome \\
\hline \multicolumn{4}{|l|}{ Mania } \\
\hline Mohan et al. (2009) & BT & $\begin{array}{l}\text { Mini Mental State Exam, Wechsler Memory } \\
\text { Scale, Scale for autobiographical memory }\end{array}$ & $\begin{array}{l}\text { MMSE and WMS scores declined in both } \\
\text { groups, but no group differences between } \\
\text { seizure threshold and } 2.5 \text { times seizure } \\
\text { threshold }\end{array}$ \\
\hline Rezaei et al. (2012) & BT & Mini Mental State Exam, Reorientation time & $\begin{array}{l}\text { MMSE scores declined in both groups } \\
\quad( \pm \text { remifentanil), but no group differences }\end{array}$ \\
\hline $\begin{array}{l}\text { Barekatain et al. } \\
(2008)\end{array}$ & BT and BF & Mini Mental State Exam & $\begin{array}{l}\text { BF group had higher MMSE scores after the 6th } \\
\text { and final ECT treatment }\end{array}$ \\
\hline Hiremani et al. (2008) & BT and BF & $\begin{array}{l}\text { Trail Making Test, Verbal Fluency Test (Cat- } \\
\text { egory), Paired Associate Learning Test, and } \\
\text { Complex Figure Test (completed after fifth } \\
\text { ECT treatment) }\end{array}$ & No group differences \\
\hline \multicolumn{4}{|l|}{ Depression } \\
\hline Kessler et al. (2014) & RUL (and pharmacotherapy) & $\begin{array}{l}\text { MATRICS Consensus Cognitive Battery, Auto- } \\
\text { biographical Memory Interview-Short Form }\end{array}$ & $\begin{array}{l}\text { Both groups demonstrated improvement in } \\
\text { every domain of MCCB with no group by } \\
\text { time interaction; AMI-SF had a group by time } \\
\text { interaction indication reduced autobiographi- } \\
\text { cal memory consistency in the ECT arm }\end{array}$ \\
\hline
\end{tabular}

bipolar state. The conflicting results in the two bifrontal/ bitemporal bipolar mania investigations may be attributed to the different assessment time points. The earlier cognitive assessment (after the fifth ECT treatment) had no differences between bitemporal and bifrontal electrode placements (Hiremani et al. 2008), but traditional 
end of ECT assessment resulted in group differences despite the use of a less sensitive cognitive measure (Barekatain et al. 2008). The right unilateral electrode placement in bipolar depression was associated with cognitive improvement on most measures and mirrored the cognitive results of pharmacotherapy arm (Kessler et al. 2014). The diminished consistency of the Autobiographical Memory Interview-Short Form must be interpreted in the context of the debatable psychometric properties of this test (Semkovska and McLoughlin 2013, 2014).

\section{Discussion}

This review focused on the relationship of electrode placement on clinical outcomes in bipolar states. Bitemporal electrode placement is the most non-focal electrode placement and has higher efficacy rates relative to more focal bifrontal and right unilateral electrode placements. An adequate ECT trial should include bitemporal electrode placement in the context of non-response with focal electrode placements (Kellner and Fink 2015). Bitemporal electrode placement should also be considered the first-line electrode placement when acuity warrants rapid response (e.g., bipolar with catatonia) (Kellner et al. 2010; Perugi et al. 2017). However, the high efficacy rates seen in bitemporal electrode placement comes at a cost of increased risk of ECT-mediated neurocognitive impairment (Semkovska et al. 2011). We hypothesized that efficacy can be maintained, and cognitive risk reduced when more focal electrode placements are matched with state-related targeted engagement. The role of targeted engagement may result in different electrode placements for different bipolar states (e.g., bifrontal for mania, unilateral for depression). The available data is insufficient to support definitive conclusions, but several patterns emerged when reviewing the data. First, focal and non-focal electrode placements are effective for all bipolar states. Second, bifrontal electrode placement appears to have equivalent efficacy relative to bitemporal electrode placement for mania and is associated with less cognitive risk (Hiremani et al. 2008; Barekatain et al. 2008). Third, the more focal electrode placements reduce the cognitive risk across different states of bipolar disorder (Kessler et al. 2014; Barekatain et al. 2008).

Electrode placement is the most important stimulation variable development with respect to geometry of the electric field and electric field current path (Peterchev et al. 2010). To date, the focus on electrode placement development has been reduction of cognitive impairment as opposed to targeting specific state-related neuroanatomic targets (d'Elia 1970; Abrams and Taylor 1973). Novel electrode placements and stimulation methods were not included in this review but represent the next developmental step in improving the risk and benefit ratio for convulsive therapies. Focal Electrically Administered Seizure (FEAST) was recently implemented with a novel electrode placement consisting of a small anode over the right eyebrow and large cathode over the right motor cortex (Nahas et al. 2013; Chahine et al. 2014; Spellman et al. 2009). The intention was to concentrate the current flow to the right subcallosal cingulate and frontal poles and avoid the medial temporal lobes. Magnetic seizure therapy is another form of brain stimulation that uses magnetic pulses to induce seizure activity (Lisanby et al. 2001a, b, 2003). The magnetic stimulation reduces the anatomic variability relevant to electric fields and creates a focal but very superficial stimulation (Lisanby et al. 2003). The cognitive profile of magnetic seizure therapy appears promising, but the clinical efficacy of FEAST and magnetic seizure therapy has yet to be established in bipolar disorder (Cretaz et al. 2015). Other efforts to improve the focality of stimulated brain volume include low amplitude seizure therapy (Radman and Lisanby 2017; Youssef and Sidhom 2017), which has yet to be thoroughly investigated with bipolar disorder. Computer modeling of the ECT induced electric field has promised even more focal methods of stimulation with reduced electrode placement size and diminished distance between stimulation electrodes (Deng et al. 2013).

As the ability to increase the focality with magnetic or electric stimulation improves, the importance of selecting the optimal target region for a diagnosis, state, phenotype or individual becomes increasingly more important. While bitemporal electrode placement may maintain high efficacy rates across different diagnoses (major depressive disorder, bipolar disorder, schizophrenia) with greater risk of cognitive impairment, more focal stimulations may miss the optimal target region for a bipolar state and compromise the efficacy of the procedure (Cretaz et al. 2015). However, the premise of this review is that the efficacy of focal stimulations may be maintained if focused on the optimal anatomic target. This framework is illustrated in a recent investigation with transcranial magnetic stimulation. Sophisticated data-driven analysis methods combined neuroimaging with depression ratings to identify distinct depression "biotypes". These biotypes successfully differentiated response to left dorsolateral or dorsomedial prefrontal cortical transcranial magnetic stimulation (Drysdale et al. 2017). Similar methods could be applied to a large sample of bipolar patients to identify phenotypes and areas of targeted engagement that may represent a more granular classification pattern than manic, depressed or mixed states.

The included investigations had several limitations that limit definitive conclusions from this review. First, the 
variability of clinical outcomes precluded formal statistical analysis. Second, the included studies were heterogeneous and included alternative outcomes not emphasized in this review (e.g., pharmacotherapy augmentation of ECT). Third, ECT parameters such as pulse width can impact both the efficacy as well as the cognitive risk of ECT but were not included in this review (Semkovska et al. 2011). Fourth, many of the included investigations relied on basic and insensitive cognitive screening measures to capture longitudinal changes in cognitive performance. Only a minority of the included studies included a thorough neuropsychological assessment (Kessler et al. 2014; Hiremani et al. 2008). Finally, seizure metrics (morphology, duration, post-ictal suppression) were not included but are related to the mood stabilizing properties of convulsive therapies.

\section{Conclusions}

Recent prospective ECT investigations with different bipolar states (depressed, manic, mixed) have assessed clinical outcomes with different electrode placements. While not definitive, the more focal electrode placements do have the potential to have equivalent efficacy, expedite the rate of response, and reduce cognitive risk. These focal electrode placements may be specific for bipolar states (e.g., bifrontal for mania). However, serious gaps in the literature preclude formal guidelines as suprathreshold right (and left) unilateral electrode placements have not been adequately assessed in bipolar mania and remain controversial in the context of optimizing ECT outcomes for bipolar disorder. If prefrontal networks are specific to bipolar mania, then bifrontal electrode placement should prove to be more efficacious than the suprathreshold unilateral treatments, but this investigation has yet to be completed. In addition, optimal targeted engagement may be more granular than the bipolar state (manic, depressed, or mixed). For example, melancholic or atypical depressive episodes have unique phenomenology and may have different patterns of aberrant circuitry that ultimately require different patterns of stimulation similar to the aforementioned "biotype" research with transcranial magnetic stimulation. Future directions include the development of more focal brain stimulation that will challenge neuroimaging research to optimally define the phenotypically-defined region for targeted engagement. Furthermore, research with more thorough cognitive assessments to disentangle state-related cognitive impairment from procedure-related cognitive impairment is needed. Accurate, focal targeted engagement of the correct anatomic circuit for a given bipolar state will optimize clinical outcomes for bipolar disorder.

\section{Authors' contributions}

CCA, JM and ML completed initial draft of manuscript, CA and JM performed literature search, CA, JM, ML, and MT conceptualized manuscript and reviewed final draft. All authors read and approved the final manuscript.

\section{Acknowledgements \\ Not applicable.}

\section{Competing interests}

Dr. Tohen was an employee of Lilly (1997 to 2008) and has received honoraria from or consulted for Abbott, AstraZeneca, Alkermes, Allergan, Bristol Myers Squibb, GlaxoSmithKline, Lilly, Johnson \& Johnson, Otsuka, Merck, Gedeon Richter Plc, Sunovion, Forest, Roche, Elan, Lundbeck, Teva, Pamlab, Minerva, Neurocrine, Pfizer, Wyeth and Wiley Publishing; his spouse was a full time employee at Lilly (1998-2013).

\section{Availability of data and materials}

Included review articles are cited in references.

\section{Consent for publication}

The authors provide consent to International Journal of Bipolar Disorders for publication.

\section{Ethics approval and consent to participate}

Not applicable for review.

Funding

$\mathrm{NIH}$ U01 MH111826 (PI: Abbott).

\section{Publisher's Note}

Springer Nature remains neutral with regard to jurisdictional claims in published maps and institutional affiliations.

Received: 21 December 2018 Accepted: 19 March 2019

Published online: 04 May 2019

\section{References}

Abbott CC, Jones T, Lemke NT, Gallegos P, McClintock SM, Mayer AR, et al. Hippocampal structural and functional changes associated with electroconvulsive therapy response. Transl Psychiatry. 2014a;4:e483.

Abbott CC, Gallegos P, Rediske N, Lemke NT, Quinn DK. A review of longitudinal electroconvulsive therapy: neuroimaging investigations. J Geriatr Psychiatry Neurol. 2014b;27(1):33-46.

Abbott CC, McClintock SM, Jones TR, Deng ZD, editors. Engaging medial temporal lobes with ECT pulse amplitude to improve clinical outcomes. West Hollywood: American College of Neuropsychopharmacology; 2016.

Abrams R, Taylor MA. Anterior bifrontal ECT: a clinical trial. Br J Psychiatry. 1973;122(570):587-90.

Anand S. Ultrabrief electroconvulsive therapy for manic episodes of bipolar disorder. J ECT. 2016;32(4):267-9.

Bailine SH, Rifkin A, Kayne E, Selzer JA, Vital-Herne J, Blieka M, et al. Comparison of bifrontal and bitemporal ECT for major depression. Am J Psychiatry. 2000;157(1):121-3.

Bailine S, Fink M, Knapp R, Petrides G, Husain MM, Rasmussen K, et al. Electroconvulsive therapy is equally effective in unipolar and bipolar depression. Acta Psychiatr Scand. 2010;121(6):431-6.

Barekatain M, Jahangard L, Haghighi M, Ranjkesh F. Bifrontal versus bitemporal electroconvulsive therapy in severe manic patients. J ECT. 2008;24(3):199-202

Blumberg HP, Leung HC, Skudlarski P, Lacadie CM, Fredericks CA, Harris BC, et al. A functional magnetic resonance imaging study of bipolar disorder: state- and trait-related dysfunction in ventral prefrontal cortices. Arch Gen Psychiatry. 2003;60(6):601-9.

Blumenfeld H, McNally KA, Ostroff RB, Zubal IG. Targeted prefrontal cortical activation with bifrontal ECT. Psychiatry Res. 2003;123(3):165-70.

Brooks JO 3rd, Vizueta N. Diagnostic and clinical implications of functional neuroimaging in bipolar disorder. J Psychiatr Res. 2014;57:12-25. 
Chahine G, Short B, Spicer K, Schmidt M, Burns C, Atoui M, et al. Regional cerebral blood flow changes associated with focal electrically administered seizure therapy (FEAST). Brain Stimul. 2014;7(3):483-5.

Ciapparelli A, Dell'Osso L, Tundo A, Pini S, Chiavacci MC, Di Sacco I, et al. Electroconvulsive therapy in medication-nonresponsive patients with mixed mania and bipolar depression. J Clin Psychiatry. 2001;62(7):552-5.

Cretaz E, Brunoni AR, Lafer B. Magnetic seizure therapy for unipolar and bipolar depression: a systematic review. Neural Plast. 2015;2015:521398.

Daly JJ, Prudic J, Devanand DP, Nobler MS, Lisanby SH, Peyser S, et al. ECT in bipolar and unipolar depression: differences in speed of response. Bipolar Disord. 2001;3(2):95-104.

d'Elia G. Unilateral electroconvulsive therapy. Acta Psychiatr Scand Suppl. 1970;215:1-98.

Deng ZD, Lisanby SH, Peterchev AV. Controlling stimulation strength and focality in electroconvulsive therapy via current amplitude and electrode size and spacing: comparison with magnetic seizure therapy. J ECT. 2013;29(4):325-35.

Dierckx B, Heijnen WT, van den Broek WW, Birkenhager TK. Efficacy of electroconvulsive therapy in bipolar versus unipolar major depression: a metaanalysis. Bipolar Disord. 2012;14(2):146-50.

Drysdale AT, Grosenick L, Downar J, Dunlop K, Mansouri F, Meng Y, et al. Resting-state connectivity biomarkers define neurophysiological subtypes of depression. Nat Med. 2017;23(1):28-38.

Gitlin M. Treatment-resistant bipolar disorder. Mol Psychiatry. 2006;11(3):227-40.

Grunhaus L, Schreiber S, Dolberg OT, Hirshman S, Dannon PN. Response to ECT in major depression: are there differences between unipolar and bipolar depression? Bipolar Disord. 2002;4(Suppl 1):91-3.

Hallam KT, Smith DI, Berk M. Differences between subjective and objective assessments of the utility of Electroconvulsive therapy in patients with bipolar and unipolar depression. J Affect Disord. 2009;112(1-3):212-8.

Heikman P, Kalska H, Katila H, Sarna S, Tuunainen A, Kuoppasalmi K. Right unilateral and bifrontal electroconvulsive therapy in the treatment of depression: a preliminary study. J ECT. 2002;18(1):26-30.

Hiremani RM, Thirthalli J, Tharayil BS, Gangadhar BN. Double-blind randomized controlled study comparing short-term efficacy of bifrontal and bitemporal electroconvulsive therapy in acute mania. Bipolar Disord. 2008;10(6):701-7.

Jahangard L, Haghighi M, Bigdelou G, Bajoghli H, Brand S. Comparing efficacy of ECT with and without concurrent sodium valproate therapy in manic patients. J ECT. 2012;28(2):118-23.

Kellner $\mathrm{CH}$, Fink M. Electroconvulsive therapy versus pharmacotherapy for bipolar depression. Am J Psychiatry. 2015;172(3):295.

Kellner CH, Knapp R, Husain MM, Rasmussen K, Sampson S, Cullum M, et al. Bifrontal, bitemporal and right unilateral electrode placement in ECT: randomised trial. Br J Psychiatry. 2010;196(3):226-34.

Kessler U, Schoeyen HK, Andreassen OA, Eide GE, Malt UF, Oedegaard KJ, et al. The effect of electroconvulsive therapy on neurocognitive function in treatment-resistant bipolar disorder depression. J Clin Psychiatry. 2014;75(11):e1306-13.

Kotzalidis GD, Pacchiarotti I, Rapinesi C, Murru A, Colom F, Vieta E. Differential effectiveness of right unilateral versus bilateral electroconvulsive therapy in resistant bipolar depression. Am J Psychiatry. 2015;172(3):294.

Lisanby SH, Luber B, Finck AD, Schroeder C, Sackeim HA. Deliberate seizure induction with repetitive transcranial magnetic stimulation in nonhuman primates. Arch Gen Psychiatry. 2001a;58(2):199-200.

Lisanby SH, Schlaepfer TE, Fisch HU, Sackeim HA. Magnetic seizure therapy of major depression. Arch Gen Psychiatry. 2001b;58(3):303-5.

Lisanby SH, Luber B, Schlaepfer TE, Sackeim HA. Safety and feasibility of magnetic seizure therapy (MST) in major depression: randomized withinsubject comparison with electroconvulsive therapy. Neuropsychopharmacology. 2003;28(10):1852-65.

MacQueen G, Parkin C, Marriott M, Begin H, Hasey G. The long-term impact of treatment with electroconvulsive therapy on discrete memory systems in patients with bipolar disorder. J Psychiatry Neurosci. 2007;32(4):241-9.

Martino M, Magioncalda P, Huang Z, Conio B, Piaggio N, Duncan NW, et al. Contrasting variability patterns in the default mode and sensorimotor networks balance in bipolar depression and mania. Proc Natl Acad Sci USA. 2016;113(17):4824-9.
McClintock SM, Choi J, Deng ZD, Appelbaum LG, Krystal AD, Lisanby SH. Multifactorial determinants of the neurocognitive effects of electroconvulsive therapy. J ECT. 2014;30(2):165-76.

Medda P, Perugi G, Zanello S, Ciuffa M, Cassano GB. Response to ECT in bipolar I, bipolar II and unipolar depression. J Affect Disord. 2009;1 18(1-3):55-9.

Medda P, Perugi G, Zanello S, Ciuffa M, Rizzato S, Cassano GB. Comparative response to electroconvulsive therapy in medication-resistant bipolar I patients with depression and mixed state. J ECT. 2010;26(2):82-6.

Medda P, Toni C, Perugi G. The mood-stabilizing effects of electroconvulsive therapy. J ECT. 2014;30(4):275-82.

Milstein V, Small JG, Klapper MH, Small IF, Miller MJ, Kellams JJ. Uni- versus bilateral ECT in the treatment of mania. Convuls Ther. 1987;3(1):1-9.

Mohan TS, Tharyan P, Alexander J, Raveendran NS. Effects of stimulus intensity on the efficacy and safety of twice-weekly, bilateral electroconvulsive therapy (ECT) combined with antipsychotics in acute mania: a randomised controlled trial. Bipolar Disord. 2009;11(2):126-34.

Nahas Z, Short B, Burns C, Archer M, Schmidt M, Prudic J, et al. A feasibility study of a new method for electrically producing seizures in man: focal electrically administered seizure therapy [FEAST]. Brain Stimul. 2013;6(3):403-8.

Nobler MS, Oquendo MA, Kegeles LS, Malone KM, Campbell CC, Sackeim HA, et al. Decreased regional brain metabolism after ect. Am J Psychiatry. 2001;158(2):305-8.

Perlis RH, Ostacher MJ, Patel JK, Marangell LB, Zhang H, Wisniewski SR, et al. Predictors of recurrence in bipolar disorder: primary outcomes from the Systematic Treatment Enhancement Program for Bipolar Disorder (STEPBD). Am J Psychiatry. 2006;163(2):217-24.

Perugi G, Medda P, Toni C, Mariani MG, Socci C, Mauri M. The role of electroconvulsive therapy (ECT) in bipolar disorder: effectiveness in 522 patients with bipolar depression, mixed-state. Mania and catatonic features. Curr Neuropharmacol. 2017;15(3):359-71.

Peterchev AV, Rosa MA, Deng ZD, Prudic J, Lisanby SH. Electroconvulsive therapy stimulus parameters: rethinking dosage. J ECT. 2010;26(3):159-74.

Prudic J, Olfson M, Marcus SC, Fuller RB, Sackeim HA. Effectiveness of electroconvulsive therapy in community settings. Biol Psychiatry. 2004:55(3):301-12.

Radman T, Lisanby SH. New directions in the rational design of electrical and magnetic seizure therapies: individualized Low Amplitude Seizure Therapy (iLAST) and Magnetic Seizure Therapy (MST). Int Rev Psychiatry (Abingdon, England). 2017;29(2):63-78.

Ranjkesh F, Barekatain M, Akuchakian S. Bifrontal versus right unilateral and bitemporal electroconvulsive therapy in major depressive disorder. J ECT. 2005;21(4):207-10.

Rezaei F, Nasseri K, Esfandiari GR, Sadeghi SM, Fathie M, Gharibi F. Remifentanil added to propofol for induction of anesthesia can reduce reorientation time after electroconvulsive therapy in patients with severe mania. J ECT. 2012;28(2):124-7.

Sackeim HA, Greenberg MS, Weiman AL, Gur RC, Hungerbuhler JP, Geschwind $N$. Hemispheric asymmetry in the expression of positive and negative emotions. Neurologic evidence. Arch Neurol. 1982;39(4):210-8.

Sackeim HA, Luber B, Katzman GP, Moeller JR, Prudic J, Devanand DP, et al. The effects of electroconvulsive therapy on quantitative electroencephalograms. Relationship to clinical outcome. Arch Gen Psychiatry. 1996;53(9):814-24.

Sackeim HA, Prudic J, Devanand DP, Nobler MS, Lisanby SH, Peyser S, et al. A prospective, randomized, double-blind comparison of bilateral and right unilateral electroconvulsive therapy at different stimulus intensities. Arch Gen Psychiatry. 2000;57(5):425-34

Schoeyen HK, Kessler U, Andreassen OA, Auestad BH, Bergsholm P, Malt UF, et al. Treatment-resistant bipolar depression: a randomized controlled trial of electroconvulsive therapy versus algorithm-based pharmacological treatment. Am J Psychiatry. 2015;172(1):41-51.

Semkovska M, McLoughlin DM. Measuring retrograde autobiographical amnesia following electroconvulsive therapy: historical perspective and current issues. J ECT. 2013;29(2):127-33.

Semkovska M, McLoughlin DM. Retrograde autobiographical amnesia after electroconvulsive therapy: on the difficulty of finding the baby and clearing murky bathwater. J ECT. 2014;30(3):187-8 (discussion 9-90).

Semkovska M, Keane D, Babalola O, McLoughlin DM. Unilateral brief-pulse electroconvulsive therapy and cognition: effects of electrode placement, stimulus dosage and time. J Psychiatr Res. 2011;45(6):770-80. 
Sienaert P, Vansteelandt K, Demyttenaere K, Peuskens J. Ultra-brief pulse ECT in bipolar and unipolar depressive disorder: differences in speed of response. Bipolar Disord. 2009;11(4):418-24.

Small JG. Efficacy of electroconvulsive therapy in schizophrenia, mania, and other disorders. II. Mania and other disorders. Convuls Ther. 1985; 1(4):271-6.

Small JG, Small IF, Milstein V, Kellams JJ, Klapper MH. Manic symptoms: an indication for bilateral ECT. Biol Psychiat. 1985;20(2):125-34.

Spellman T, Peterchev AV, Lisanby SH. Focal electrically administered seizure therapy: a novel form of ECT illustrates the roles of current directionality, polarity, and electrode configuration in seizure induction. Neuropsychopharmacology. 2009;34(8):2002-10.

Strakowski SM, Eliassen JC, Lamy M, Cerullo MA, Allendorfer JB, Madore M, et al. Functional magnetic resonance imaging brain activation in bipolar mania: evidence for disruption of the ventrolateral prefrontal-amygdala emotional pathway. Biol Psychiat. 2011;69(4):381-8.
Strakowski SM, Fleck DE, Welge J, Eliassen JC, Norris M, Durling M, et al. fMRI brain activation changes following treatment of a first bipolar manic episode. Bipolar Disord. 2016;18(6):490-501.

Thirthalli J, Kumar CN, Bangalore RP, Gangadhar BN. Speed of response to threshold and suprathreshold bilateral ECT in depression, mania and schizophrenia. J Affect Disord. 2009;117(1-2):104-7.

Thirthalli J, Prasad MK, Gangadhar BN. Electroconvulsive therapy (ECT) in bipolar disorder: a narrative review of literature. Asian J Psychiatr. 2012;5(1):11-7.

UK ECT Review Group. Efficacy and safety of electroconvulsive therapy in depressive disorder: a systematic review and meta-analysis. Lancet. 2003;361:799-808.

Youssef NA, Sidhom E. Feasibility, safety, and preliminary efficacy of Low Amplitude Seizure Therapy (LAP-ST): a proof of concept clinical trial in man. J Affect Disord. 2017;222:1-6.

\section{Submit your manuscript to a SpringerOpen ${ }^{\odot}$ journal and benefit from:}

- Convenient online submission

- Rigorous peer review

- Open access: articles freely available online

- High visibility within the field

- Retaining the copyright to your article

Submit your next manuscript at springeropen.com 